\title{
Research
}

\section{The role of the basolateral amygdala in punishment}

\author{
Philip Jean-Richard-Dit-Bressel and Gavan P. McNally \\ School of Psychology, The University of New South Wales, Sydney, New South Wales, Australia
}

\begin{abstract}
Aversive stimuli not only support fear conditioning to their environmental antecedents, they also punish behaviors that cause their occurrence. The amygdala, especially the basolateral nucleus (BLA), has been critically implicated in Pavlovian fear learning but its role in punishment remains poorly understood. Here, we used a within-subjects punishment task to assess the role of the BLA in the acquisition and expression of punishment as well as aversive choice. Rats that pressed two individually presented levers for pellet rewards rapidly suppressed responding to one lever if it also caused footshock deliveries (punished lever) but continued pressing a second lever that did not cause footshock (unpunished lever). Infusions of GABA agonists baclofen and muscimol (BM) into the BLA significantly impaired the acquisition of this suppression. BLA inactivations using $B M$ also reduced the expression of well-trained punishment. There was anatomical segregation within the BLA so that caudal, not rostral, BLA was implicated in punishment. However, when presented with punished and unpunished levers simultaneously in a choice test without deliveries of shock punisher, rats expressed a preference for unpunished over the punished lever and BLA inactivations had no effect on this preference. Taken together, these findings indicate that the BLA is important for both the acquisition and expression of punishment but not for aversive choice. This role appears to be linked to neurons in the caudal BLA, rather than rostral BLA, although the circuitry that contributes to this functional segregation is currently unknown, and is most parsimoniously interpreted as a role for caudal BLA in determining the aversive value of the shock punisher.
\end{abstract}

Aversive reinforcement, such as delivery of footshock, can have two distinct consequences for learning and behavior. First, it supports learning about its environmental antecedents to imbue such stimuli with the ability to elicit conditioned responses. In this way, animals learn to fear a stimulus that signals occurrence of footshock and will express species-typical defense reactions upon subsequent presentations of that stimulus. Second, aversive reinforcement supports learning about its behavioral antecedents and alters the probability that these behaviors will be emitted again in the future. In this way, animals learn to withhold or reduce a behavior that causes delivery of footshock. These two consequences of aversive reinforcement, fear and punishment, are linked to the actions of different learning processes. Fear is due to the operation of Pavlovian conditioning and formation of associations between the CS and the shock US. Punishment is due to the operation of instrumental aversive learning and the formation of an association between a response and the shock punisher (Bolles 1975; Bolles et al. 1980; Mackintosh 1980; Goodall 1984).

Much progress has been made in understanding the brain mechanisms for Pavlovian fear conditioning. Using Pavlovian fear conditioning with a shock US, a variety of lines of evidence implicate the amygdala in aversive reinforcement (Maren and Quirk 2004). Principal cells of lateral and basolateral nuclei (BLA) receive glutamatergic inputs from thalamus and cortex conveying information about the CS and US (Sah et al. 2003; Marek et al. 2013). The strength of these inputs varies as a consequence of learning so that CS inputs are strengthened (Maren and Quirk 2004), whereas US inputs are weakened (Johansen et al. 2010). The actions of glutamate at NMDA receptors are essential for this plasticity as well as fear learning (Maren and Quirk 2004). Thus in rodents, BLA lesions, reversible inactivation, or microinjections of NMDA receptor antagonists, among other manipulations, each impair acquisition of Pavlovian fear learning (Maren and Quirk 2004). In humans, amygdala damage likewise impairs fear learning and neuroimaging studies show a robust and reliable

\section{Corresponding author: g.mcnally@unsw.edu.au}

Article is online at http://www.learnmem.org/cgi/doi/10.1101/lm.035907.114. change in the blood oxygenation level-dependent signal in the human amygdala during fear learning (Sehlmeyer et al. 2009).

The role of the BLA in punishment is less well understood. Given its central role in instrumental association formation, in particular, in encoding the values of specific outcomes (Corbit and Balleine 2005; Parkes and Balleine 2013) and its welldocumented sensitivity to aversive stimuli, it is highly likely that the BLA is important for punishment. Indeed, several lines of evidence implicate the amygdala in punishment. For example, in rodents, infusions of norepinephrine or benzodiazepines into the amygdala reduce the effectiveness of shock as an instrumental punisher and punishment itself increases $\mathrm{GABA}_{\mathrm{A}}$ receptor subunit mRNA expression and benzodiazepine binding in the amygdala (Margules 1971; Liu and Glowa 2000). Similar anti-punishment effects have been observed with serotonin-depleting amygdala lesions (Sommer et al. 2001). In humans, fMRI studies have also implicated the amygdala in punishment. In these studies, punishment has been achieved via different approaches (e.g., monetary loss, loss feedback), and fMRI shows amygdala activation (Zalla et al. 2000) and amygdala interactions with the ventral striatum (Camara et al. 2009) and hippocampus (Hahn et al. 2010). There is also evidence that sensitivity to punishment, as assessed via self-report, positively correlates with amygdala volume (BarrósLoscertales et al. 2006). Finally, a study of humans with bilateral amygdala lesions (Bechara et al. 1999) showed that they, unlike healthy controls, did not learn to avoid choosing from disadvantageous decks in the Iowa Gambling Task. Nonetheless, neither these rodent nor human studies have adequately isolated the role of the BLA versus other amygdala regions in punishment. Lesion studies in rats, enabling greater anatomical control, have been better able to isolate an effect to the BLA. For example,

(C) 2015 Jean-Richard-Dit-Bressel and McNally This article is distributed exclusively by Cold Spring Harbor Laboratory Press for the first 12 months after the full-issue publication date (see http://learnmem.cshlp.org/site/misc/terms. xhtml). After 12 months, it is available under a Creative Commons License (Attribution-NonCommercial 4.0 International), as described at http:// creativecommons.org/licenses/by-nc/4.0/. 
Killcross et al. (1997) reported that excitotoxic lesions of the BLA, but not the central amygdala, impaired conditioned punishment whereby lever-pressing was punished via presentations of an aversive CS. Yet these lesion studies have not adequately distinguished between the roles of the BLA in different aspects of punishment (e.g., acquisition, expression, aversive choice), and the role of the BLA in instrumental aversive learning has been disputed (Maren 2003).

There are also differences in connectivity (Sesack et al. 1989; Brog et al. 1993; Shinonaga et al. 1994; McDonald et al. 1996; Alheid 2003; Hamlin et al. 2009) and function (Kantak et al. 2002; McLaughlin and Floresco 2007; Hamlin et al. 2009) between the rostral and caudal BLA which have not been explored in regard to punishment. For example, caudal but not rostral BLA projects extensively to the prelimbic prefrontal cortex (PL), whereas rostral BLA receives more PL inputs than caudal BLA. In addition, whereas caudal BLA projects extensively to medial portion of the nucleus accumbens shell, rostral BLA projects to lateral portions of the nucleus accumbens shell (Groenewegen et al. 1999). Consistent with this differential connectivity, caudal BLA has been implicated in extinction of instrumental responding (McLaughlin and Floresco 2007; Hamlin et al. 2009), whereas rostral BLA has been implicated in reinstatement of extinguished instrumental responding (Kantak et al. 2002). Given that caudal and rostral BLA have differing inputs, outputs, and functions, including a distinct caudal BLA role in extinction of instrumental responding (which, similar to punishment, can be considered a form of reward behavior suppression), the contributions of caudal and rostral BLA to punishment were also examined.

The aim of Experiment 1 was to establish a multiphase punishment task assessing the acquisition and expression of punishment as well aversive choice (Table 1). The aim of Experiment 2 was to study the role of BLA in this punishment task. Rats received bilateral cannulation of the BLA permitting reversible inactivation using the $\mathrm{GABA}_{\mathrm{A}}$ and $\mathrm{GABA}_{\mathrm{B}}$ receptor agonists muscimol and baclofen, respectively, and were then subjected to behavioral training (Table 1). The initial phase involved a between-group manipulation assessing the role of BLA in the acquisition of punishment. The next phases involved within-group manipulation investigating the role of BLA in expression of punishment and instrumental aversive choice. Finally, rats were assessed for the effects of BLA inactivation on locomotor activity.

\section{Results}

\section{Experiment 1: assessment of multiphase punishment paradigm}

\section{Pretraining}

In daily 40-min pretraining sessions, rats received alternating periods of $5 \mathrm{~min}$ access to two levers whereby each lever was reinforced with a food pellet on a VI30s schedule for $7 \mathrm{~d}$. One rat was excluded from all analyses due to a failure to acquire leverpressing to either lever during pretraining. Mean and SEM of lever-pressing, freezing, and latency to initial lever-press on the last day of pretraining are shown in Figure 1A-C. There was no significant difference in responding on the to-be punished and to-be unpunished levers as measured by lever-pressing $\left(F_{(1,6)}<1 ; P>\right.$ $0.05)$ or average latency to initially lever-press $\left(F_{(1,6)}<1 ; P>\right.$
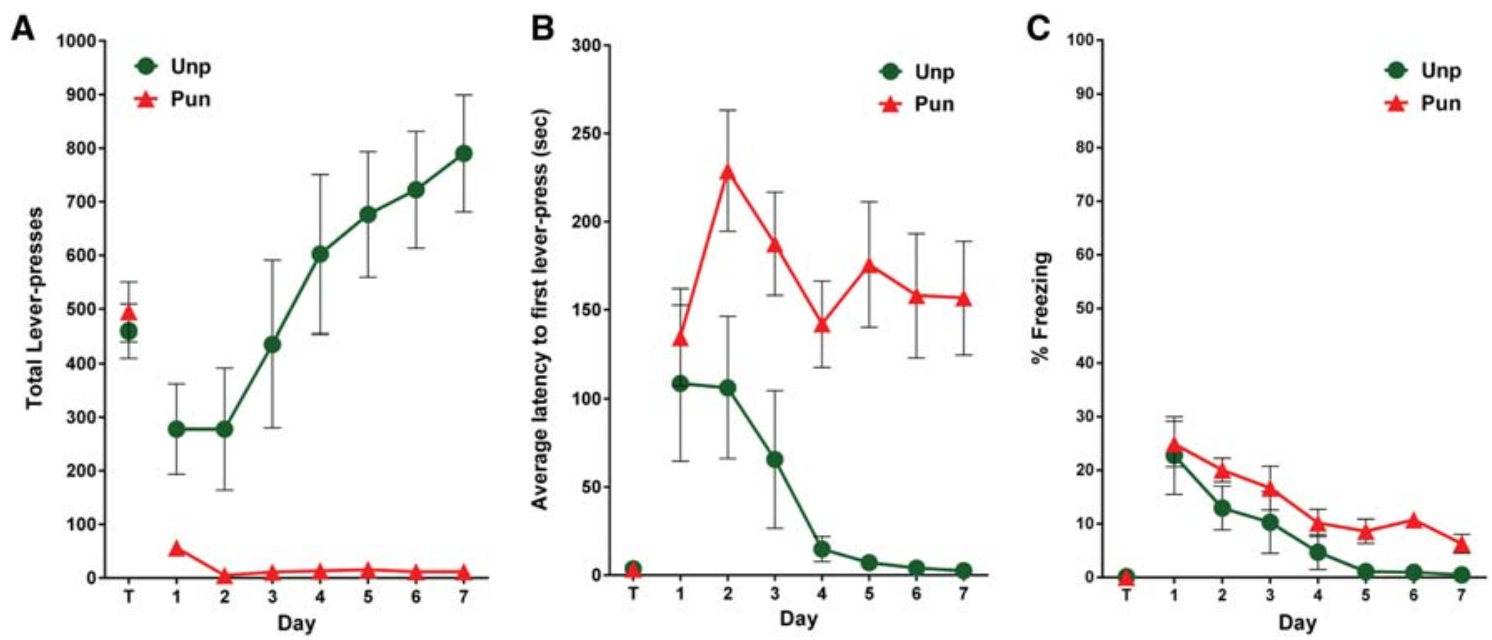

Figure 1. (A) Mean \pm SEM lever-presses on the punished and unpunished levers for the last day of pretraining $(T)$ and punishment sessions (Days 1-7; $n=7)$. (B) Mean \pm SEM latency to initially press the punished and unpunished lever (averaged across trials) for the last day of pretraining $(T)$ and punishment sessions. (C) Mean \pm SEM levels of freezing while punished and unpunished levers were extended for the last day of pretraining $(T)$ and punishment sessions. 
0.05) on the last day of pretraining. There was also no difference in freezing while the punished and to-be unpunished levers were extended $\left(F_{(1,6)}<1 ; P>0.05\right)$ on the last day of pretraining.

\section{Punishment}

Following pretraining, rats received daily 40 min daily punishment sessions consisting of alternating periods of 5 min access to two levers for $7 \mathrm{~d}$. Pressing these levers was reinforced with food pellets via the same VI30s schedule used during pretraining, and one of these levers was also punished on an FR10 schedule with delivery of footshock.

Mean \pm SEM lever-pressing during the punishment phase are shown in Figure 1A. Over the course of this training, there was a significant effect of lever (punished versus unpunished), $\left(F_{(1,6)}=\right.$ $25.5 ; P<0.05)$ and the difference in responding on the levers increased across days, $\left(F_{(1,6)}=30.7 ; P<0.05\right)$. Across days, there was an increase in responding on the unpunished lever $\left(F_{(1,6)}=27.3\right.$; $P<0.05)$ and a decrease in responding on the punished lever $\left(F_{(1,6)}=38.3 ; P<0.05\right)$.

Mean \pm SEM latencies to initially lever-press during the punishment phase are shown in Figure 1B. There was an overall decrease in latencies to press levers across days $\left(F_{(1,6)}=8.3 ; P<\right.$ 0.05 ). There was also a significant effect of lever (punished versus unpunished) $\left(F_{(1,6)}=34.2 ; P<0.05\right)$. No significant interaction between lever and day was observed $\left(F_{(1,6)}=4.6 ; P>0.05\right)$, though there was a significant decrease in latencies to press the unpunished lever $\left(F_{(1,6)}=7.3 ; P<0.05\right)$ but no significant change in latencies to press the punished lever $\left(F_{(1,6)}=1.1 ; P>0.05\right)$.

We assessed expression of the species-typical defense of freezing during each session each day. Mean \pm SEM levels of freezing during the punishment phase are shown in Figure 1C. Freezing was initially low ( $\sim 20 \%$ of observations) and significantly decreased across the course of punishment training. Over the course of this training, there was a significant effect of which lever was extended (punished versus unpunished) $\left(F_{(1,6)}=7.5 ; P<0.05\right)$ and a significant decrease of freezing across days $\left(F_{(1,6)}=23.7 ; P<\right.$ $0.05)$. There was no lever $\times$ day interaction $\left(F_{(1,16)}<1 ; P>0.05\right)$, with freezing decreasing across days for both the punished $\left(F_{(1,16)}=61.8 ; P<0.05\right)$ and unpunished lever $\left(F_{(1,16)}=12.2 ; P<\right.$ $0.05)$. Importantly, there was no significant correlation between freezing and responding on the punished lever $\left(r_{x y}=0.236, n=\right.$ $49, P>0.05)$. So, although there was some freezing in this task, it was low, it decreased across the course of punishment, and explained only $5.5 \%$ of the variance in punished lever responding.

\section{Aversive choice}

Following the punishment expression test, rats were assessed in a choice procedure across $2 \mathrm{~d}$ that involved simultaneous presentations of both the punished and unpunished lever in $30 \mathrm{~min}$ sessions. Each lever was reinforced with food pellets on a VI60s schedule, but no punishment was delivered. A punished session was given between the two choice sessions.

Figure 2A shows responses on choice test and Figure 2B shows latencies to responses. Rats responded significantly more on the unpunished than the punished lever $\left(F_{(1,6)}=34.7 ; P<0.05\right)$, with no lever $\times$ day interaction $\left(F_{(1,6)}=1.4 ; P>0.05\right)$. No significant overall effect of lever $\left(F_{(1,6)}=4.9 ; P>0.05\right)$, day $\left(F_{(1,6)}=2.0\right.$; $P>0.05)$, or lever $\times$ day interaction $\left(F_{(1,6)}=2.1 ; P>0.05\right)$ on lever-press latency was found. So, rats displayed a preference for responding on the unpunished lever that was stable across two test days and although latencies were faster on the second test day than the first, this decrease was not significant. Freezing during choice test was low and did not exceed $5 \%$ of observations.
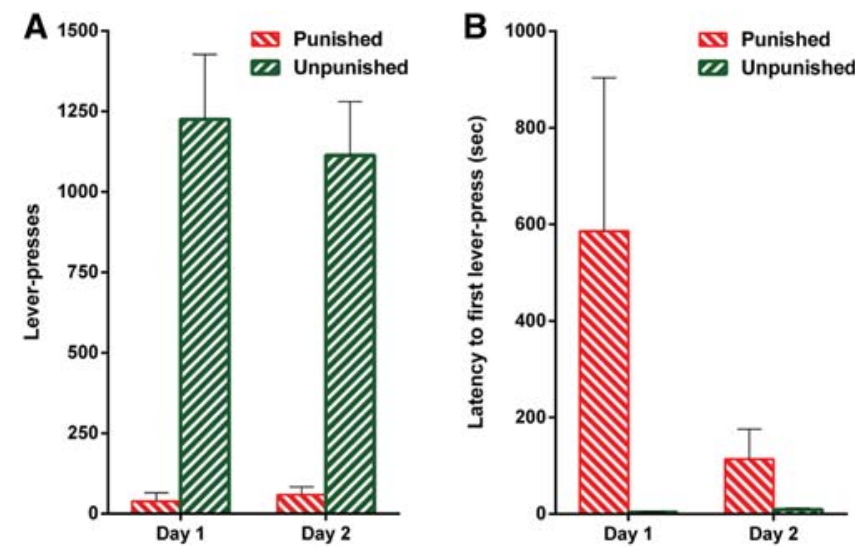

Figure 2. (A) Mean \pm SEM lever-presses on the punished and unpunished levers across the $2 \mathrm{~d}$ of aversive choice task. (B) Mean \pm SEM latency to initially press the punished and unpunished lever across the $2 \mathrm{~d}$ of aversive choice task.

\section{Experiment 2: role of the BLA in punishment \\ Histology}

The locations of microinjection cannulae are shown in Figure 3. Examination of placements revealed that four rats had misplaced cannulae and did not bilaterally target the BLA. These animals with misplaced cannulae were excluded from the analyses, leaving 18 animals remaining. Of these 18 animals, nine had placements that were located in rostral BLA and nine had placements that were located in caudal BLA.

\section{Pretraining}

In daily 40 min pretraining sessions, rats received alternating periods of $5 \mathrm{~min}$ access to two levers whereby each lever was reinforced with a food pellet on a VI30s schedule for $7 \mathrm{~d}$. The mean \pm SEM responses on the to-be-punished and to-be-unpunished levers are shown in Figure 4A. There was no significant overall difference between saline and $\mathrm{BM}$ groups in lever-pressing at the end of pretraining $\left(F_{(1,16)}<1 ; P>0.05\right)$, no overall difference in responding on the to-be-punished and to-be-unpunished levers $\left(F_{(1,16)}=1.4 ; P>0.05\right)$, and no group $\times$ lever interaction $\left(F_{(1,16)}=2.9 ; P>0.05\right)$.

\section{Effects of BLA inactivation on acquisition of punishment}

In the five 40-min daily punishment sessions, rats had alternating periods of $5 \mathrm{~min}$ access to two levers. These levers were reinforced with food pellets via the same VI30s schedule used during pretraining, and one of these levers was also punished on an FR10 schedule with delivery of footshock. Rats received infusions into the BLA immediately prior to the first $2 \mathrm{~d}$ of punishment training.

The mean \pm SEM lever-pressing during the punishment phase are shown in Figure 4A. Over the course of this training, there was a significant effect of lever (punished versus unpunished), $\left(F_{(1,16)}=35.3 ; P<0.05\right)$ and the difference in responding on the levers increased across days, $\left(F_{(1,16)}=51.4 ; P<0.05\right)$. Across days, there was an increase in responding on the unpunished lever $\left(F_{(1,16)}=35.7 ; P<0.05\right)$ and a decrease in responding on the punished lever $\left(F_{(1,16)}=36.8 ; P<0.05\right)$.

Rats received BLA infusions of $\mathrm{BM}$ or saline prior to the first $2 \mathrm{~d}$ of training. During these infusion days, responding on the punished lever $\left(F_{(1,16)}=6.3 ; P<0.05\right)$, but not responding on the unpunished lever $\left(F_{(1,16)}<1 ; P>0.05\right)$, was significantly 

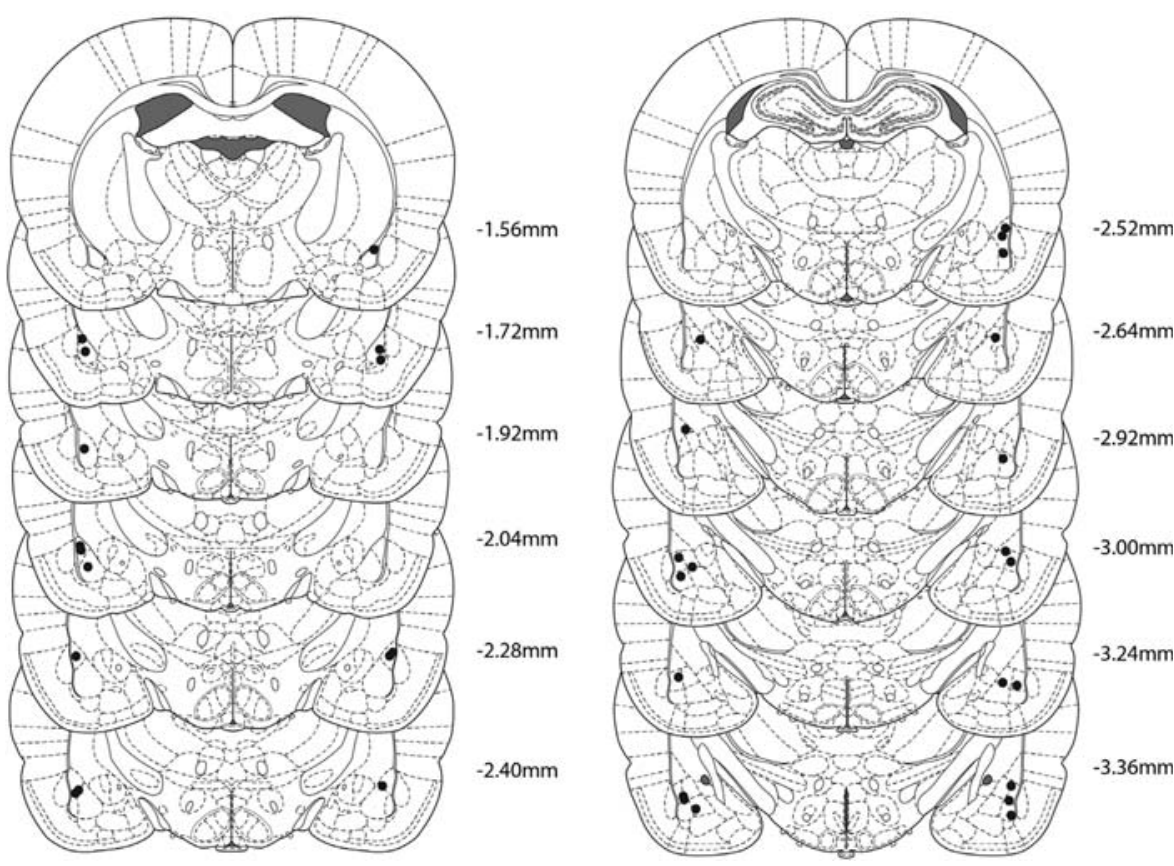

Figure 3. Microinfusion cannula placements within the BLA as verified by Nissl-stained sections. Black dots represent the most ventral point of the cannula tract, indicated on coronal sections adapted from Paxinos and Watson (2007). Cannulations anterior to $-2.6 \mathrm{~mm}$ from Bregma were considered as targeting the rostral BLA, while those posterior to $-2.6 \mathrm{~mm}$ were considered as targeting the caudal BLA. of lever, such that rats responded more on the unpunished lever than the punished lever $\left(F_{(1,17)}=58.6 ; \quad P<0.05\right)$. There was no difference in responding between $\mathrm{BM}$ and saline tests for the unpunished lever $\left(F_{(1,17)}<1 ; \quad P>0.05\right)$ and the difference between these tests for the punished lever approached, but did not reach, statistical significance $\left(F_{(1,17)}=4.1 ; P=0.059\right)$. There was no effect of acquisition group (saline versus $\mathrm{BM})$ on lever-pressing during expression test (all $\left.F_{(1,16)}<1 ; P>0.05\right)$.

To further examine the effects of BLA inactivation on expression of punishment, responding on punished and unpunished levers was computed as a ratio of responding between the $\mathrm{BM}$ and saline tests (ratio $=A /(A+B)$ ) (Fig. 5B). When this ratio equals 0.5 , responding on the lever did not change between the $\mathrm{BM}$ and saline tests, whereas values $>0.5$ indicate an increase in responding on the BM test and values $<0.5$ indicate a decrease in responding on the BM test. BM significantly increased this ratio on the punished lever relative to the unpunished lever $\left(F_{(1,17)}=5.7 ; P<0.05\right)$. This was due to the punished lever-press ratio being significantly $>0.5\left(t_{(17)}=2.4\right.$; $P<0.05)$ while the unpunished ratio was

affected by BM infusions, so BM infusions increased responding on the punished but not unpunished levers. There were no differences between groups on the remaining three infusion free days (all $F_{(1,16)}<1.3$; all $P>0.05$ ). We also assessed latencies to emit first responses across trials on the punished and unpunished lever during infusion days (Fig. 4B). During these infusion days, latencies to respond on the punished lever increased $\left(F_{(1,16)}=9.5 ; \quad P<0.05\right)$, whereas latencies to respond on the unpunished lever did not $\left(F_{(1,16)}<1 ; P>0.05\right)$. There was no effect of BM infusions on these latencies for either the punished $\left(F_{(1,16)}=1.4\right.$; $P>0.05)$ or unpunished $\left(F_{(1,16)}<1 ; P>\right.$ $0.05)$ lever.

\section{Effects of BLA inactivation on expression of punishment}

At the end of training rats were tested twice, once after BLA infusion of BM and once after infusion of saline, for the effects of BLA inactivation on the expression of punishment. The order of these tests was counterbalanced. These tests were conducted in the same manner as the punishment acquisition sessions and so involved 5 min alternating presentations of the two levers reinforced on the same VI30s (food pellet) and FR10 (footshock) schedules as acquisition.

The mean and SEM levels of performance on test are shown in Figure $5 \mathrm{~A}$. There was a significant main effect
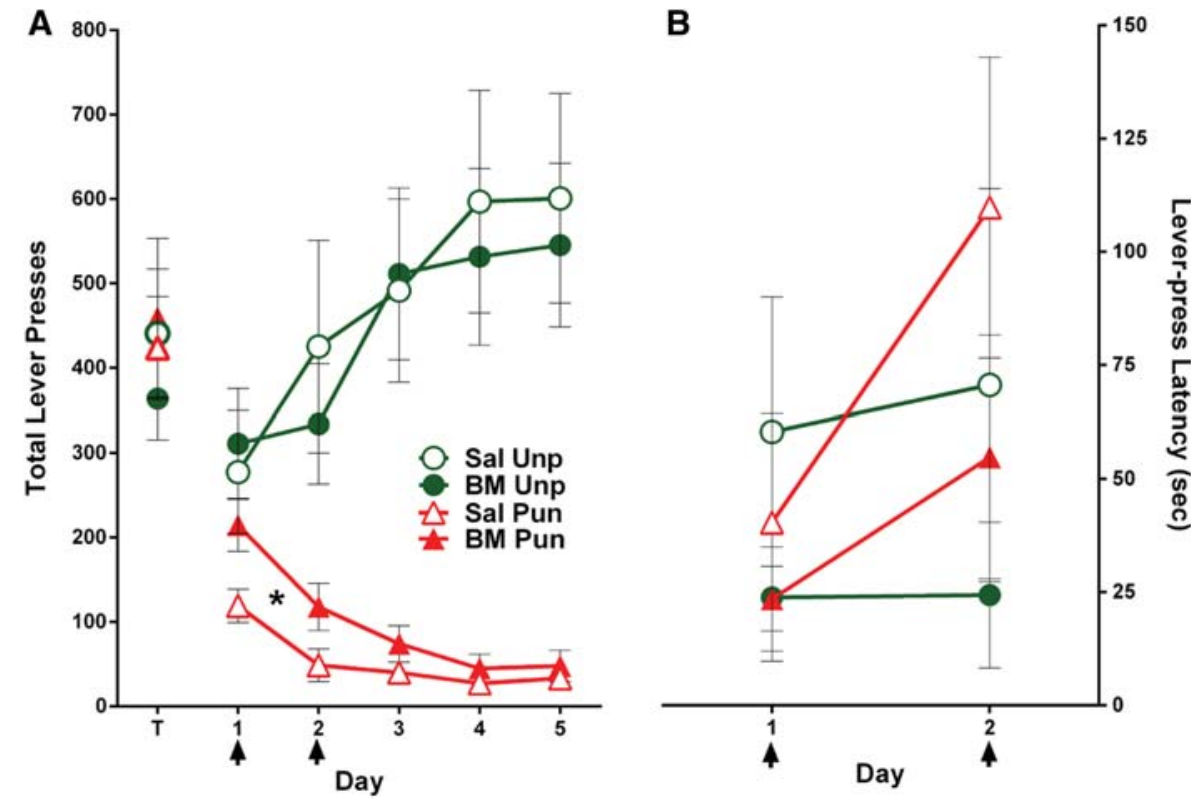

Figure 4. (A) Mean \pm SEM lever-presses on the punished and unpunished levers during the last day of pretraining $(T)$ and punishment acquisition. Arrows indicate days that rats received infusions of either saline $(n=9)$ or baclofen and muscimol $(\mathrm{BM})(n=9)$ immediately prior to the session. (B) Mean \pm SEM latency to initially press the punished and unpunished lever (averaged across trials) during punishment acquisition. (*) $P<0.05$. 

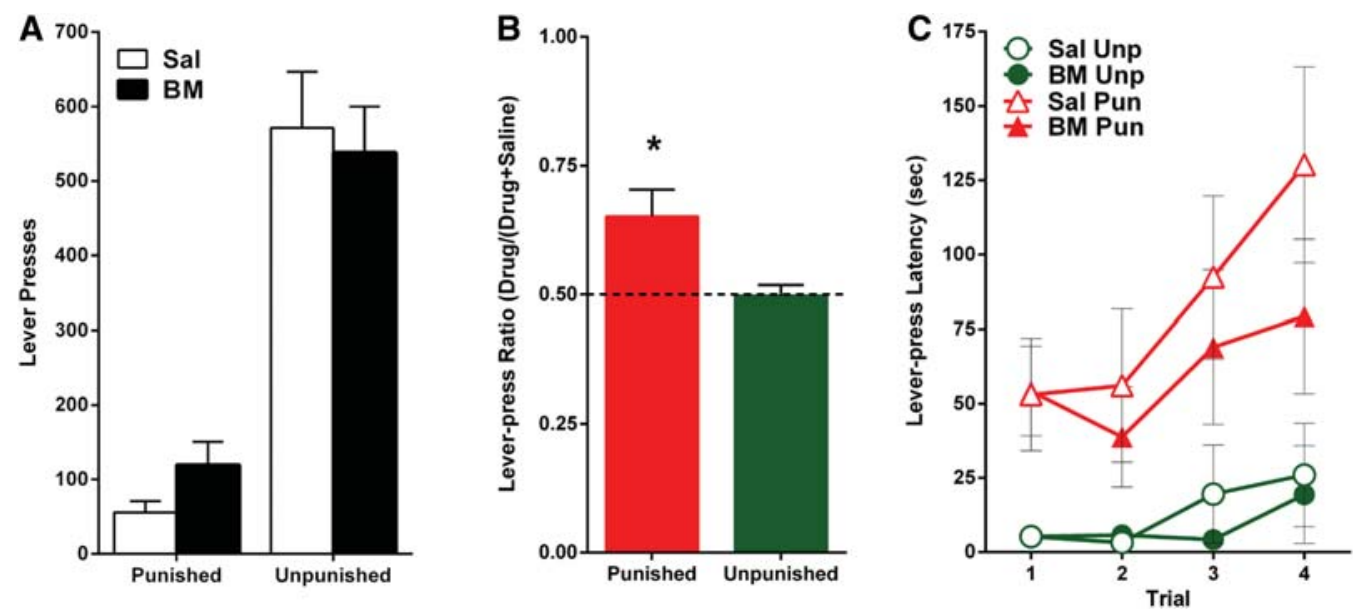

Figure 5. (A) Mean \pm SEM lever-presses on the punished and unpunished levers during punishment expression. Rats received within-subject infusions of saline and BM $(n=18)$ immediately prior to the session, counterbalanced across days. (B) Mean \pm SEM suppression ratios of BM on lever-pressing during punishment expression. (C) Mean \pm SEM latency to initially press the punished and unpunished lever across trials, after infusions of saline or BM, during punishment expression. $\left(^{*}\right) P<0.05$.

unpunished lever $\left(F_{(1,17)}=17.9 ; P<0.05\right)$ and there was a significant overall increase in latencies to respond across the session $\left(F_{(1,17)}=5.1 ; P<0.05 ;\right.$ Fig. $\left.5 \mathrm{C}\right)$. This was due to increased latencies to press the punished lever $\left(F_{(1,17)}=6.9 ; P<0.05\right)$, while there was no significant change in latencies to press the unpunished lever $\left(F_{(1,17)}=1 ; P>0.05\right)$. BM infusion into BLA had no significant effect on these latencies (all $F_{(1,17)}<2.4 ; P>0.05$ ).

The results of Experiment 1 showed that the preference for the unpunished lever during choice test-both in terms of responses and latency to response-did not change significantly across the two test days. We examined whether the effects of BLA infusions depended on whether animals were infused first, as compared with second with BM. There was no interaction of infusion order on lever-presses, latencies (all $F_{(1,15)}<1 ; P>0.05$ ), or within-session lever-presses (all $F_{(1,15)}<2.2 ; P>0.05$ ).

BLA cannula placements varied from -2.28 to $-3.36 \mathrm{~mm}$ relative to Bregma. There are differences in connectivity (Sesack et al. 1989; Brog et al. 1993; Shinonaga et al. 1994; McDonald et al. 1996; Alheid 2003; Hamlin et al. 2009) and function (Kantak et al. 2002; McLaughlin and Floresco 2007; Hamlin et al. 2009) between the rostral and caudal BLA. Hence, further analyses were conducted to determine whether the effects of BM infusions on expression of punishment depended on whether rostral or caudal BLA was targeted. Using a criterion of $-2.6 \mathrm{~mm}$ from Bregma to separate rostral and caudal BLA (McLaughlin and Floresco 2007; Hamlin et al. 2009), nine subjects were identified as having caudal BLA placements and nine subjects as having rostral placements.

Overall, rats with caudal $\left(F_{(1,8)}=57.7 ; P<0.05\right)$ and rostral $\left(F_{(1,8)}=16.6 ; P<0.05\right)$ placements responded significantly less on the punished lever compared with the unpunished lever (Fig. $6 \mathrm{~A})$. However, infusions of BM into the caudal BLA caused a significant increase in responding on the punished $\left(F_{(1,8)}=5.3 ; p<\right.$ $0.05)$ but not the unpunished lever $\left(F_{(1,8)}<1 ; P>0.05\right)$. In contrast, infusions of BM into the rostral BLA had no significant effect
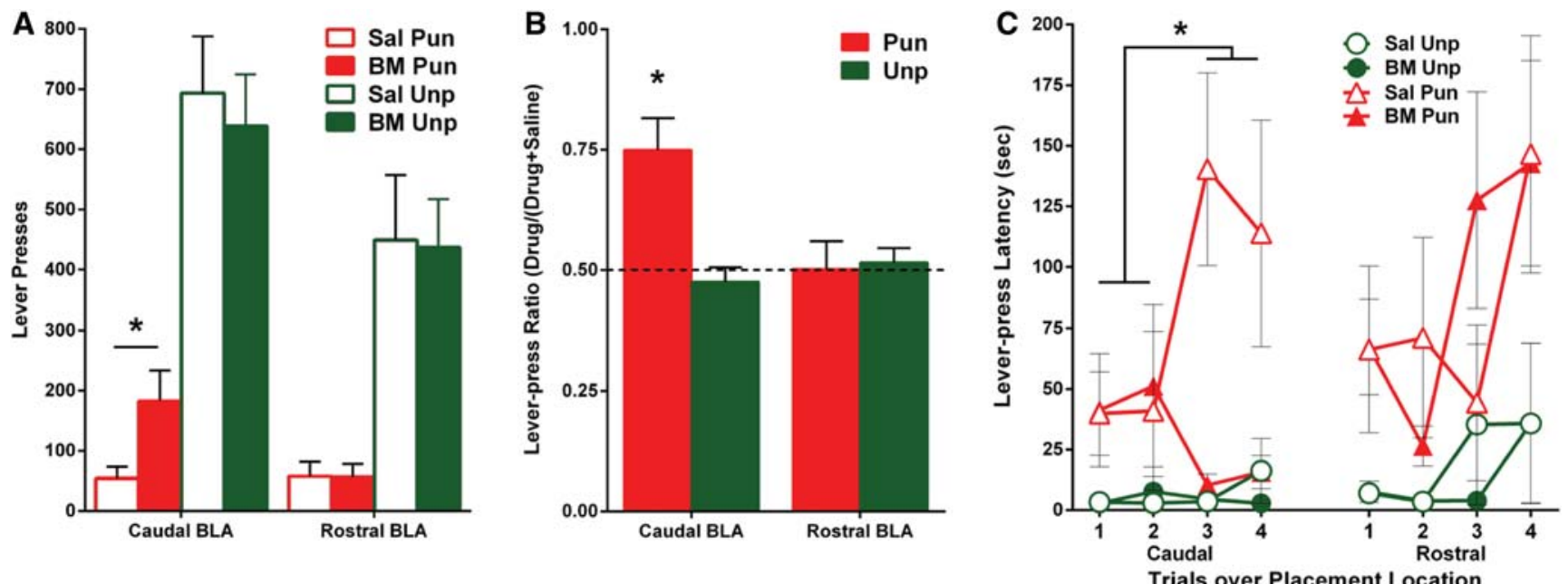

Figure 6. (A) Mean \pm SEM lever-presses on the punished and unpunished levers during punishment expression, separated into rats with cannulae targeting caudal $(n=9)$ and rostral $(n=9)$ portions of the BLA. (B) Mean \pm SEM suppression ratios of BM on lever-pressing during punishment expression, separated into caudal and rostral BLA-targeting cannulae. (C) Mean \pm SEM latency to initially press the punished and unpunished lever across trials during punishment expression, separated into caudal and rostral BLA-targeting cannulae. $\left(^{*}\right) P<0.05$. 
on responding on either lever $\left(F_{(1,8)}<1 ; P>0.05\right)$. There was also a significant increase in the BM:Saline lever-press ratio for the punished lever compared with the unpunished lever for caudal $\left(F_{(1,8)}=29.1 ; P<0.05\right)$ but not rostral BLA $\left(F_{(1,8)}<1 ; P>0.05\right.$; Fig. $6 \mathrm{~B})$. This was due to the lever-press ratio for caudal BLA being significantly $>0.5$ for the punished lever $\left(t_{(8)}=3.7 ; P<\right.$ $0.05)$ while the unpunished ratio was no different from 0.5 $\left(t_{(8)}=-0.81 ; P>0.05\right)$. Infusions of BM into the rostral BLA did not significantly change the lever-press ratios from 0.5 for either lever (punished: $t_{(8)}=0.04 ; P>0.05$; unpunished: $t_{(8)}=0.5 ; P>$ 0.05 ). There was no effect of acquisition group (saline versus $\mathrm{BM}$ ) on lever-pressing or lever-press ratios for either caudal or rostral BLA rats (all $F_{(1,7)}<2 ; P>0.05$ ).

BM infusion into the caudal BLA also had a significant effect on lever-press latencies (Fig. 6C). Specifically, overall, rats with caudal $\left(F_{(1,8)}=6.9 ; P<0.05\right)$ and rostral $\left(F_{(1,8)}=10.4 ; P<0.05\right)$ placements were significantly slower to respond on the punished lever compared with the unpunished lever. However, BM infusion into caudal BLA decreased latency to respond on the punished $\left(F_{(1,8)}=8.4 ; P<0.05\right)$ but not the unpunished lever $\left(F_{(1,8)}<1\right.$; $P>0.05)$. Critically, this effect of $\mathrm{BM}$ interacted with trials $\left(F_{(1,8)}=7.7 ; P<0.05\right)$ so that response latencies to the punished lever increased over the session after saline infusions into the caudal BLA $\left(F_{(1,8)}=5.6 ; P<0.05\right)$, while response latencies to the punished lever after BM infusions did not significantly change over the session $\left(F_{(1,8)}=2.2 ; P>0.05\right)$. BM into the rostral BLA had no significant effect on lever-press latencies (all $F_{(1,8)}<2.3$; all $P>0.05)$.

\section{Effects of BLA inactivation on aversive choice}

Following the punishment expression test, rats were assessed in a choice procedure across $2 \mathrm{~d}$ that involved simultaneous presentations of both the punished and unpunished lever in 30 min sessions. Each lever was reinforced with food pellets on a VI60s schedule, but no punishment was delivered. Rats received infusions prior to the two tests (baclofen/muscimol and saline, counterbalanced).

One rat was excluded due to a damaged cannula. Figure 7A shows responses on choice test and Figure 7B shows latencies to responses. Rats responded significantly more on the unpunished than the punished lever $\left(F_{(1,16)}=38.9 ; P<0.05\right)$. There was no difference in responding between $\mathrm{BM}$ and saline tests for the unpunished lever $\left(F_{(1,16)}<1 ; P>0.05\right)$ or punished lever $\left(F_{(1,16)}<1\right.$; $P>0.05)$. Rats were also significantly slower to respond on the punished relative to the unpunished lever $\left(F_{(1,16)}=11.5 ; P<\right.$ $0.05)$. However, there was no effect of BM infusions on lever-press latencies (all $F_{(1,16)}<2.7 ; P>0.05$ ). There was no significant increase in punished lever-presses across the $30 \mathrm{~min}$ sessions $\left(F_{(1,16)}=3.2 ; P>0.05\right)$, and no interaction between changes in punished lever-pressing across choice test sessions and infusion of BM $\left(F_{(1,16)}<1 ; P>0.05\right)$. Further analysis of these data by location of BLA cannula did not alter these main findings.

\section{Effects of BLA inactivation on locomotor activity}

Last, rats were placed in a plain locomotor chamber for $40 \mathrm{~min}$ over $3 \mathrm{~d}$. They received $\mathrm{BM}$ and saline infusions immediately prior to the last $2 \mathrm{~d}$ (counterbalanced across days). BM infusions into the BLA had no effect on locomotor activity. This was regardless of whether total distance traveled $\left(F_{(1,16)}=1.6 ; P>0.05\right.$; Fig. 7C) or average velocity $\left(F_{(1,16)}=3.3 ; P>0.05\right.$; Fig. 7D) was assessed. This finding was also unaffected by location of cannulae-neither BM infusions into the caudal BLA nor rostral BLA affected distance traveled or velocity $(F \mathrm{~s}<2.1 ; P>0.05)$.

\section{Discussion}

These experiments studied the behavioral phenomenon of punishment and the role of the BLA in punishment by reversibly inactivating the BLA, using baclofen/muscimol (BM), during various punishment-influenced tasks. Control animals (Experiment 1 and Experiment 2 saline infused rats) learned to reduce responding on the punished lever across the course of punishment training and the latencies with which animals responded on this lever increased. In contrast, responding on the unpunished lever increased and latencies to respond on this lever remained low. When confronted with a choice between the unpunished versus punished lever, but in the absence of any punishment, rats showed a clear preference for the unpunished lever both in terms of total lever-presses as well as latencies to respond on the two levers. Experiment 1 revealed that the contribution of Pavlovian fear, via freezing, to these effects was minimal.
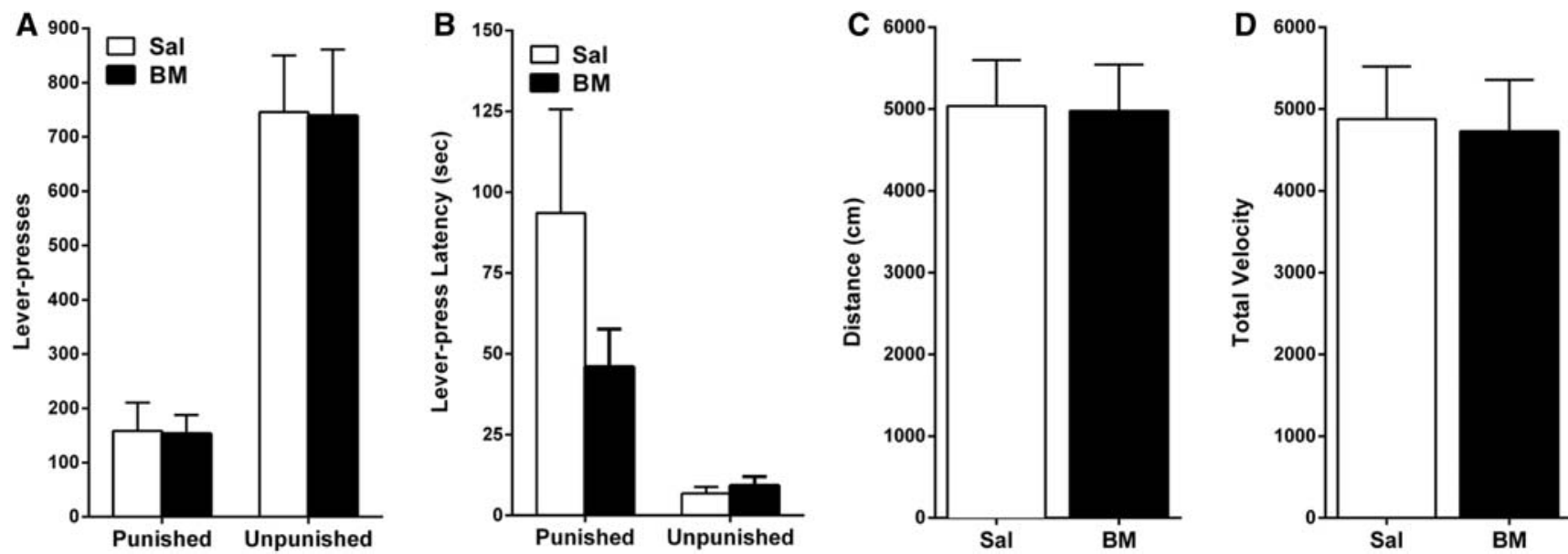

Figure 7. (A) Mean \pm SEM lever-presses on the punished and unpunished levers during the aversive choice task. Rats received within-subject infusions of saline and BM $(n=17)$ immediately prior to the session, counterbalanced across days. (B) Mean \pm SEM latency to initially press the punished and unpunished lever during the aversive choice task. (C) Mean \pm SEM distance traveled after within-subject infusions of saline and BM ( $n=17)$, counterbalanced across days. $(D)$ Mean \pm SEM total velocity after within-subject infusions of saline and BM $(n=17)$, counterbalanced across days. 
Reversible inactivation of the BLA had significant but selective and anatomically specific effects on punishment. First, BLA inactivation significantly impaired the initial acquisition of punishment so that BM animals responded more on the punished lever than saline controls. Second, inactivation of the caudal but not the rostral BLA significantly reduced the expression of punishment as shown by significantly more responses on the punished lever between saline and BM tests, a significantly increased ratio of responses on these two tests, and significantly faster latencies to respond on the punished lever. These effects show that caudal but not rostral BLA is important for punishment. Nonetheless, there was no evidence here that BLA, either caudal or rostral, was important for choice between the punished and unpunished levers as measured by responses on either levers or latencies to respond on these levers.

These effects are consistent with a role for the BLA in determining the aversive value of the shock punisher. Three lines of evidence support this interpretation. First, BLA inactivation increased responding on the punished lever, consequently increasing the number of shocks that the animals received. Second, the impact of BLA inactivation depended on the presence of the punisher and was not observed in its absence; BLA inactivation had robust effects on performance during sessions when the shock punisher was delivered but there was no effect on performances in the choice test when the punisher was absent. The requirement of the footshock punisher to be present to detect an effect of BLA inactivation could be interpreted as BLA being important for footshock sensitivity. However, inactivation of the BLA (via lesions or reversible inactivations using muscimol or APV) does not affect rats' sensitivity to footshock (Maren et al. 1996; Rabinak and Maren 2008). Third, latency data from expression tests showed a dual effect of punishment. There was an increased latency to respond on the punished lever compared with the unpunished lever that was present at the start of the session, prior to any shock being delivered. There was also a second increase in these latencies across the session after shock had been delivered. BLA inactivation had no effect on initial latencies to respond on the punished lever. These inactivations did, however, prevent the increase in latencies across the session.

A key finding here was that there were differences between rostral and caudal BLA involvement in punishment. In fact, BLA contributions to punishment were difficult to detect when rostral and caudal inactivations were aggregated. This might explain why previous considerations of a role for the BLA (that did not account for a rostro-caudal subdivision) in instrumental aversive learning have been somewhat ambiguous (Maren 2003). The differences in connectivity between the rostral and caudal BLA (Sesack et al. 1989; Brog et al. 1993; Shinonaga et al. 1994; McDonald et al. 1996; Groenewegen et al. 1999; Hamlin et al. 2009; Alheid 2003), such as caudal but not rostral BLA projecting extensively to the prelimbic prefrontal cortex (PL) and medial portion of the nucleus accumbens shell, could indicate an anatomically distinct circuit for punishment processing. Consistent with this differential connectivity, caudal BLA has been implicated in extinction of instrumental responding (McLaughlin and Floresco 2007; Hamlin et al. 2009), which can be considered another form of appetitive-motivated behavior suppression, whereas rostral BLA has been contrastingly implicated in reinstatement of extinguished instrumental responding (Kantak et al. 2002). The role for caudal BLA in both punishment and extinction of instrumental responding could reflect this subregion's general role in suppression of appetitively motivated behavior. Given the caudal BLA-AcbSh pathway has been shown to mediate appetitive extinction expression (Millan and McNally 2011) and the role of PL in action-outcome contingency encoding (Cardinal et al. 2003; Corbit and Balleine 2003), these structures could be considered strong candidates for mediating punishment. However, the role of the specific connectivity of caudal BLA (e.g., PL, AcbSh) in the acquisition and expression of punishment as well as aversive choice remains to be determined.

Given the well-documented role for the BLA in fear learning and its role here in punishment, it is worth commenting on the relationship between punishment and fear conditioning. Early in punishment training or when there is a weak contingency between the response and the shock, Pavlovian fear conditioning can contribute to reductions in responding (Bolles 1975; Bolles et al. 1980; Goodall 1984). However, this effect is observed on both the punished and unpunished levers (i.e., conditioned suppression), and the influence of Pavlovian associations is considerably reduced across the course of punishment training and/or when there is a strong response-shock contingency such as during the fixed ratio used here (Bolles 1975; Bolles et al. 1980; Goodall 1984). Here we measured behavioral freezing responses during the punishment task. There was no evidence that the selective undermining of responding on the punished lever by shock was attributable to competition from the species-specific defense response of freezing. Overall levels of freezing were low and they significantly decreased across the course of punishment training. This decrease in freezing concomitant with a decrease in punished lever-pressing is precisely the opposite to that expected if competition from freezing were reducing responding on the punished lever. Moreover, during the final punishment sessions and choice test, freezing occurred on $<10 \%$ of all observations. Given the very low levels of freezing in the experiment, which decreased as the punishment task was learned, and the lack of evidence for a role of freezing in selectively undermining responding on the punished lever, it is difficult to link the effects of BLA infusions, which were specific to responding on the punished lever, to an effect on freezing.

Taken together, these findings support the conclusion that the BLA is important for both the acquisition and expression of punishment but not for aversive choice. This role appears to be linked to neurons in the caudal BLA, rather than rostral BLA, although the circuitry that contributes to this functional segregation is currently unknown, and is most parsimoniously interpreted as a role for caudal BLA in determining the aversive value of the shock punisher.

\section{Materials and Methods}

\section{Experiment 1: assessment of multiphase punishment paradigm}

\section{Subjects}

Subjects were eight experimentally naïve male Sprague Dawley rats (290-340 g) obtained from a commercial supplier (Animal Resources Centre, Perth, Australia). Rats were housed in groups of four in plastic cages and maintained on a 12-h light-dark cycle (lights on at 7:00 a.m.). The procedures used were approved by the Animal Care and Ethics Committee at the University of New South Wales and were conducted in accordance with the National Institutes of Health (NIH) Guide for the Care and Use of Laboratory Animals (NIH Publications No. 80-23, revised 1996).

\section{Apparatus}

All behavioral training was conducted in a set of eight identical experimental chambers $(24 \mathrm{~cm}$ [length] $\times 30 \mathrm{~cm}$ [width] $\times 21$ $\mathrm{cm}$ [height]; Med Associates Inc.). Each chamber was enclosed in sound- and light-attenuating cabinets $(55.9 \mathrm{~cm}$ [length] $\times$ $35.6 \mathrm{~cm}$ [width] $\times 38.1 \mathrm{~cm}$ [height]) and fitted with fans for ventilation and background noise. The chambers were made up of a Perspex rear-wall, ceiling and hinged front-wall, and stainless steel 
sidewalls. The chamber floors were made of stainless steel rods (4 $\mathrm{mm}$ in diameter) spaced $15 \mathrm{~mm}$ apart. Each chamber stood $35 \mathrm{~mm}$ above a tray of corncob bedding. A recessed magazine (3 $\mathrm{cm}$ in diameter) within a $4 \times 4 \mathrm{~cm}$ hollow in the right-side chamber wall received pellets from an external automatic hopper. Infrared photocells detected entries into the magazine. Infrared webcams, attached to the ceiling of the cabinets, recorded all activity within the chamber from above.

Two retractable levers were placed either side of the magazine. In both experiments, a $45 \mathrm{~g}$ grain pellet, which was delivered to the magazine from the external hopper, served as the reward. The punisher was a $0.5 \mathrm{sec}, 0.5 \mathrm{~mA}$ footshock delivered through the grid floor. All chambers were connected to a computer with Med-PC IV software (Med Associates), which controlled lever, pellet, and shock presentations and recorded the lever-presses and magazine entries.

\section{Procedure}

Lever-press training. Commencing $5 \mathrm{~d}$ after surgery and persisting for the duration of the experiment, rats received daily access to 10$15 \mathrm{~g}$ of food and unrestricted access to water in their home cages. Three days after commencement of this feeding schedule, rats were placed in the experimental chambers for $30 \mathrm{~min}$ to acclimatize and were then given lever-press training, which consisted of two levers (left and right) being extended and reinforced with grain pellets on a fixed ratio-1 (FR-1) schedule for $1 \mathrm{~h}$, or until each lever had been pressed 25 times each (each lever would retract after 25 presses). Houselights were on throughout the session. All rats received another day of leverpress training, and any rats that did not acquire lever-pressing were manually shaped until lever-pressing was acquired. However, one rat failed to acquire lever-pressing, even after attempts at shaping, and was excluded from the experiment. All rats were then given $7 \mathrm{~d}$ of lever-press training. Levers were presented individually in an alternating pattern so that one lever was extended for 5 min while the other lever was retracted. After $5 \mathrm{~min}$ the extended lever was retracted and the retracted lever was extended, such that each lever was always presented on its own. This alternation occurred throughout the $40 \mathrm{~min}$ session. Both levers were reinforced with a pellet on a VI30s schedule.

Punishment. On Days 1-8, rats were trained and tested in the punishment task. Punishment sessions were identical to acquisition sessions, except that a designated lever was also punished with a $0.5 \mathrm{sec}, 0.5-\mathrm{mA}$ footshock on an FR-10 schedule. The same lever (left or right) was designated as "punished" throughout the experiment for each rat but which lever was designated as punished was counterbalanced between rats.

Choice test. On Days 9 and 11 rats received a choice test. This involved both levers being extended for $30 \mathrm{~min}$. Responses on either lever were rewarded on a VI60s such that pressing only one lever or both levers over the course of the session yielded no benefit. No shocks were delivered. Between the two choice tests, rats received a reminder punished session, under the same conditions as the previous punished sessions, to reduce any effects the initial nonreinforced session might have had on performance or lever preference.

\section{Data analysis}

The dependent measures were total punished and unpunished lever-pressing per session, average latency to initially lever-press punished and unpunished levers, and freezing (defined as a crouching posture with the absence of all movement other than that required for respiration) during punished and unpunished trials. Within-subjects ANOVAs were used to analyze all data, with lever (punished versus unpunished) and day (using linear contrasts) as the two factors for punishment and aversive choice. A correlation analysis between freezing and lever-pressing was also conducted, with the total number of lever-presses during a session correlated with the amount of freezing observed for that session (seven rats, seven sessions each $=49$ data points). For all analyses, type I error rate $(\alpha)$ was controlled at 0.05 . Rats were excluded from all analyses if they failed to acquire lever-pressing during pretraining.

\section{Experiment 2: role of the BLA in punishment}

\section{Subjects}

Subjects were 22 experimentally naïve male Sprague Dawley rats (300-380 g) obtained from a commercial supplier (Animal Resources Centre, Perth, Australia). Rats were housed in groups of four in plastic cages and maintained on a 12-h light-dark cycle (lights on at 7:00 a.m.). The procedures used were approved by the Animal Care and Ethics Committee at the University of New South Wales and were conducted in accordance with the National Institutes of Health (NIH) Guide for the Care and Use of Laboratory Animals (NIH Publications No. 80-23, revised 1996).

\section{Apparatus}

All apparatus was identical to Experiment 1. Additionally, locomotor activity was assessed in Plexiglas chambers (Med Associates) $43.2 \mathrm{~cm}$ (width) $\times 43.2 \mathrm{~cm}$ (length) $\times 30.5 \mathrm{~cm}$ (height) for $40 \mathrm{~min}$. Movement was tracked through the use of three 16 beam infrared arrays. Infrared beams were located on both the $X$ and $Y$-axes for positional tracking.

\section{Procedure}

Surgery. Rats were anesthetized with $1.3 \mathrm{~mL} / \mathrm{kg}$ ketamine $(100 \mathrm{mg} /$ $\mathrm{mL}$; Ketapex; Apex Laboratories) and $0.2 \mathrm{~mL} / \mathrm{kg}$ muscle relaxant, xylazine (20 mg/mL; Rompun; Bayer) (i.p.) and placed in stereotaxic apparatus (Model 900, Kopf), with the incisor bar maintained at $\sim 3.3 \mathrm{~mm}$ below horizontal to achieve a flat skull position. Twenty-six gauge guide cannulae $(11 \mathrm{~mm}$ in length; Plastics One) were implanted bilaterally according to the coordinates AP: -2.9 , ML: $\pm 5.0, \mathrm{DV}:-7.9 \mathrm{~mm}$ from bregma when targeting the caudal BLA $(n=12)$, and AP: -2.1 , ML: \pm 4.9 , DV: $-7.9 \mathrm{~mm}$ from bregma when targeting the rostral BLA $(n=10)$ (Paxinos and Watson 2007). The guide cannulae were fixed in position with dental cement and jeweller's screws. Dummy cannulae were kept in the guide at all times except during microinjections. Rats were allowed to recover for $5 \mathrm{~d}$ prior to the start of the experimental procedure.

Lever-press training. Commencing $5 \mathrm{~d}$ after surgery and persisting for the duration of the experiment, rats received daily access to 10-15 $\mathrm{g}$ of food and unrestricted access to water in their home cages. Three days after commencement of this feeding schedule, rats were placed in the experimental chambers for $30 \mathrm{~min}$ to acclimatize and were then given lever-press training, which consisted of two levers (left and right) being extended and reinforced with grain pellets on a fixed ratio-1 (FR-1) schedule for $1 \mathrm{~h}$, or until each lever had been pressed 25 times each (each lever would retract after 25 presses). Houselights were on throughout the session. All rats received another day of leverpress training, and any rats that did not acquire lever-pressing were manually shaped until lever-pressing was acquired. All rats were then given $7 \mathrm{~d}$ of lever-press training. Levers were presented individually in an alternating pattern so that one lever was extended for $5 \mathrm{~min}$ while the other lever was retracted. After $5 \mathrm{~min}$ the extended lever was retracted and the retracted lever was extended, such that each lever was always presented on its own. This alternation occurred throughout the $40 \mathrm{~min}$ session. Both levers were reinforced with a pellet on a VI30s schedule.

Punishment. On Days 1-8, rats were trained and tested in the punishment task. Punishment sessions were identical to acquisition sessions, except that a designated lever was also 
punished with a $0.5 \mathrm{sec}, 0.5-\mathrm{mA}$ footshock on an FR-10 schedule. The same lever (left or right) was designated as "punished" throughout the experiment for each rat but which lever was designated as punished was counterbalanced between rats. Immediately before the first $2 \mathrm{~d}$ of Phase I, rats received bilateral infusions of $0.9 \%$ phosphate-buffered saline or of the GABA agonists baclofen and muscimol (BM; $1 \mathrm{mM}$ baclofen, $0.1 \mathrm{mM}$ muscimol; Sigma-Aldrich) to assess the role of BLA in the acquisition of punishment. For microinjections, a 33-gauge microinjection cannula (Plastics One) was inserted into the guide cannula and connected to a $10 \mu \mathrm{L}$ glass syringe (Hamilton Company) operated by an infusion pump (World Precision Instruments). The microinjection cannula projected a further 1 $\mathrm{mm}$ ventral to the tip of the guide cannula. Drugs were infused at a rate of $0.25 \mu \mathrm{L} / \mathrm{min}$ over $2 \mathrm{~min}$, and the microinjection cannula was left in place for a further 1 min to permit diffusion of the injectate. Rats also received bilateral infusions of either saline or BM on Days 6 and 7 (counterbalanced, within subject) to test for the effect of BLA inactivation on expression of punishment.

Choice test. On Days 9 and 11 rats received a choice test. This involved both levers being extended for $30 \mathrm{~min}$. Responses on either lever were rewarded on a VI-60 s such that pressing only one lever or both levers over the course of the session yielded no benefit. No shocks were delivered. Rats were tested twice, once after bilateral infusions of $\mathrm{BM}$ and once after infusions of saline (within subject, counterbalanced). Between the two choice tests, rats received a reminder punished session, under the same conditions as the previous punished sessions, to reduce any effects the initial nonreinforced session might have had on performance or lever preference.

Locomotor test. On Day 13, rats were placed in locomotor chambers for $40 \mathrm{~min}$ to habituate them to the chamber. Days 14 and 15, rats received bilateral BLA infusions of saline or BM (counterbalanced, within subject) immediately before being placed into the locomotor chambers for $40 \mathrm{~min}$. Total distance traveled and velocities were measured.

Histology. At the end of the experiment, the rats were injected i.p. with sodium pentobarbital $(100 \mathrm{mg} / \mathrm{kg})$ and their brains were removed. Unfixed brains were quickly frozen and sectioned coronally $(40 \mu \mathrm{m})$ through the BLA using a cryostat (Microm 560). Each section was collected and subsequently stained with cresyl violet for histological examination. The boundaries of the BLA were determined according to Paxinos and Watson (2007).

\section{Data analysis}

The dependent measures were total punished and unpunished lever-pressing per session and latency to lever-press. Between $\times$ within-subjects ANOVAs were used to analyze lever-press training and punishment acquisition (Phase I) data, with lever (punished versus unpunished) and day (for punishment acquisition, using linear contrasts) as the within-subjects factors, and drug group (Saline versus BM) as the between-subjects factor. Within-subjects ANOVAs were used to analyze lever-presses and lever-press latencies for punishment expression, aversive choice and locomotor test (Phases II, III, and IV). In these analyses, lever (punished versus unpunished) was one within-subjects factor and infusion (saline versus BM) was the other. To analyze the role of punishment acquisition infusions on punishment expression, a betweensubjects factor of acquisition group (saline versus BM) was added to the punishment expression within-subjects ANOVA. To analyze the role of initial infusion on aversive choice a betweensubjects factor of initial infusion (saline versus BM) was added to the aversive choice within-subjects ANOVA. To analyze withinsession changes in punished lever-pressing during the aversive choice test, including any effect of BLA inactivation, punished lever-presses for each minute was used as one within-subjects factor (using a linear contrast) and infusion (saline versus BM) was used as another factor. Lever-press ratios were analyzed using a one-sample $t$-test, using 0.5 (no change in lever-pressing after drug compared with after saline) as the test value. For all analyses, type I error rate $(\alpha)$ was controlled at 0.05 . Rats were excluded from all analyses if they failed to acquire lever-pressing during pretraining or if the cannula tip was not bilaterally located within the BLA.

\section{Acknowledgments}

These experiments were supported by a grant from the Australian Research Council (DP130100310) to G.P.M. P.J.R.D.B. was supported by a UNSW International Research Scholarship and G.P.M. was supported by a Future Fellowship (FT120100250) from the Australian Research Council.

\section{References}

Alheid GF. 2003. Extended amygdala and basal forebrain. Ann N Y Acad Sci 985: $185-205$.

Barrós-Loscertales A, Meseguer V, Sanjuán A, Belloch V, Parcet MA, Torrubia R, Avila C. 2006. Behavioural inhibition system activity is associated with increased amygdala and hippocampal gray matter volume: a voxel-based morphometry study. Neuroimage 33: 1011-1015.

Bechara A, Damasio H, Damasio AR, Lee GP. 1999. Different contributions of the human amygdala and ventromedial prefrontal cortex to decision-making. J Neurosci 19: 5473-5481.

Bolles RC. 1975. Theory of motivation. Harper \& Row, New York.

Bolles RC, Holtz R, Dunn T, Hill W. 1980. Comparisons of stimulus learning and response learning in a punishment situation. Learn Motiv 11: 78-96.

Brog JS, Salyapongse A, Deutch AY, Zahm DS. 1993. The patterns of afferent innervation of the core and shell in the "Accumbens" part of the rat ventral striatum: immunohistochemical detection of retrogradely transported fluoro-gold. J Comp Neurol 338: 255-278.

Camara E, Rodriguez-Fornells A, Münte TF. 2009. Functional connectivity of reward processing in the brain. Front Hum Neurosci 2: 19.

Cardinal RN, Parkinson JA, Hall J, Everitt BJ. 2003. The contribution of the amygdala, nucleus accumbens, and prefrontal cortex to emotion and motivated behaviour. International Congress Series 1250: 347-370.

Corbit LH, Balleine BW. 2003. The role of prelimbic cortex in instrumental conditioning. Behav Brain Res 146: 145-157.

Corbit LH, Balleine BW. 2005. Double dissociation of basolateral and central amygdala lesions on the general and outcome-specific forms of pavlovian-instrumental transfer. J Neurosci 25: 962-970.

Goodall G. 1984. Learning due to the response-shock contingency in signalled punishment. Q J Exp Psychol 36B: 259-279.

Groenewegen HJ, Wright CI, Beijer AV, Voorn P. 1999. Convergence and segregation of ventral striatal inputs and outputs. Ann N Y Acad Sci 877: $49-63$.

Hahn T, Dresler T, Plichta MM, Ehlis AC, Ernst LH, Markulin F, Polak T, Blaimer M, Deckert J, Lesch KP, et al. 2010. Functional amygdalahippocampus connectivity during anticipation of aversive events is associated with Gray's trait "sensitivity to punishment". Biol Psychiatry 68: $459-464$.

Hamlin AS, Clemens KJ, Choi EA, McNally GP. 2009. Paraventricular thalamus mediates context-induced reinstatement (renewal) of extinguished reward seeking. Eur J Neurosci 29: 802-812.

Johansen JP, Tarpley JW, LeDoux JE, Blair HT. 2010. Neural substrates for expectation-modulated fear learning in the amygdala and periaqueductal gray. Nat Neurosci 13: 979-986.

Kantak KM, Black Y, Valencia E, Green-Jordan K, Eichenbaum HB. 2002. Dissociable effects of lidocaine inactivation of the rostral and caudal basolateral amygdala on the maintenance and reinstatement of cocaine-seeking behavior in rats. J Neurosci 22: 1126-1136.

Killcross S, Robbins TW, Everitt BJ. 1997. Different types of fear-conditioned behaviour mediated by separate nuclei within amygdala. Nature 388: 377-380.

Liu M, Glowa JR. 2000. Regulation of benzodiazepine receptor binding and $\mathrm{GABA}_{\mathrm{A}}$ subunit mRNA expression by punishment and acute alprazolam administration. Brain Res 887: 23-33.

Mackintosh NJ. 1980. Conditioning and associative learning. Oxford University Press, Oxford, UK.

Marek R, Strobel C, Bredy TW, Sah P. 2013. The amygdala and medial prefrontal cortex: partners in the fear circuit. J Physiol 591: 2381-2391.

Maren S. 2003. What the amygdala does and doesn't do in aversive learning. Learn Mem 10: 306-308.

Maren S, Quirk GJ. 2004. Neuronal signalling of fear memory. Nat Rev Neurosci 5: 844-852. 
Maren S, Aharonov G, Stote DL, Fanselow MS. 1996. N-methyl-D-aspartate receptors in the basolateral amygdala are required for both acquisition and expression of conditioned fear in rats. Behav Neurosci 110: 13651374.

Margules DL. 1971. Localization of anti-punishment actions of norepinephrine and atropine in amygdala and entopeduncular nucleus of rats. Brain Res 35: 177-184.

McDonald AJ, Mascagni F, Guo L. 1996. Projections of the medial and lateral prefrontal cortices to the amygdala: a Phaseolus vulgaris leucoagglutinin study in the rat. Neurosci 71: 55-75.

McLaughlin RJ, Floresco SB. 2007. The role of different subregions of the basolateral amygdala in cue-induced reinstatement and extinction of food-seeking behavior. Neuroscience 146: 1484-1494.

Millan EZ, McNally GP. 2011. Accumbens shell AMPA receptors mediate expression of extinguished reward seeking through interactions with basolateral amygdala. Learn Mem 18: 414-421.

Parkes SL, Balleine BW. 2013. Incentive memory: evidence the basolateral amygdala encodes and insular cortex retrieves outcome values to guide choice between goal-directed actions. J Neurosci 33: 8753-8763.

Paxinos G, Watson C. 2007. The rat brain in stereotaxic coordinates. Elsevier, New York.

Rabinak CA, Maren S. 2008. Associative structure of fear memory after basolateral amygdala lesions in rats. Behav Neurosci 122: 1284-1294.
Sah P, Faber ES, Lopez De Armentia M, Power J. 2003. The amygdaloid complex: anatomy and physiology. Physiol Rev 83: 803-834.

Sehlmeyer C, Schöning S, Zewisterlood P, Pfeliderer B, Kircher T, Arolt V, Konrad C. 2009. Human fear conditioning and extinction in neuroimaging: a systematic review. PLoS One 4: e5865.

Sesack SR, Deutsch HR, Roth RH, Bunney BS. 1989. Topographical organization of the efferent projections of the medial prefrontal cortex in the rat: An anterograde tract-tracing study with Phaseolus vulgaris leucoagglutinin. J Comp Neurol 290: 213-242.

Shinonaga Y, Takada M, Mizuno N. 1994. Topographic organization of collateral projections from the basolateral amygdaloid nucleus to both the prefrontal cortex and nucleus accumbens in the rat. Neurosci 58: 389-397.

Sommer W, Moller C, Wiklund L, Thorsell A, Rimondini R, Nissbrandt H, Heilig M. 2001. Local 5,7-dihydroxytryptamine lesions of rat amygdala: release of punished drinking, unaffected plus-maze behaviour and ethanol consumption. Neuropsychopharmacology 24: 430-440.

Zalla T, Koechlin E, Pietrini P, Basso G, Aquino P, Sirigu A, Grafman J. 2000. Differential amygdala response to winning and losing: a functional magnetic imaging study in humans. Eur J Neurosci 12: 1764-1770.

Received May 29, 2014; accepted in revised form October 14, 2014. 


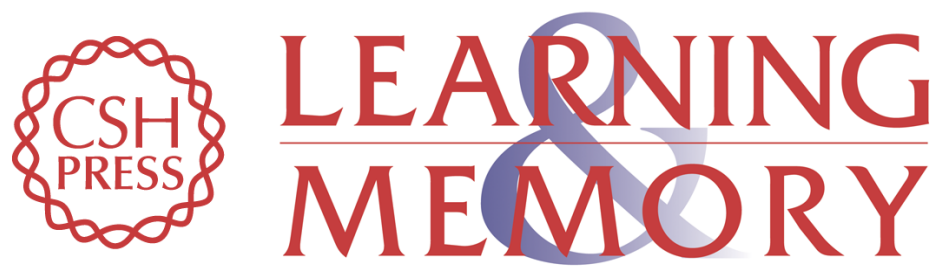

\section{The role of the basolateral amygdala in punishment}

Philip Jean-Richard-Dit-Bressel and Gavan P. McNally

Learn. Mem. 2015, 22:

Access the most recent version at doi:10.1101//m.035907.114

References This article cites 33 articles, 6 of which can be accessed free at: http://learnmem.cshlp.org/content/22/2/128.full.html\#ref-list-1

Creative This article is distributed exclusively by Cold Spring Harbor Laboratory Press for the Commons first 12 months after the full-issue publication date (see

License http://learnmem.cshlp.org/site/misc/terms.xhtml). After 12 months, it is available under a Creative Commons License (Attribution-NonCommercial 4.0 International), as described at http://creativecommons.org/licenses/by-nc/4.0/.

Email Alerting Receive free email alerts when new articles cite this article - sign up in the box at the Service top right corner of the article or click here. 